\title{
Response processes and semantic-context effects
}

\author{
MARK DALLAS and PHILIP M. MERIKLE \\ University of Waterloo, Waterloo, Ontario, Canada N2L 3G1
}

\begin{abstract}
When semantic context reduces the time required to name a visually presented target word, it is usually assumed to operate at an early stage in the word-recognition process. In two experiments, presentation of a pair of words was followed more than $1 \mathrm{sec}$ later by a cue to name one of the two words. In Experiment I, the word pairs were presented for $150 \mathrm{msec}$; in Experiment II, presentation of the word pairs continued until subjects initiated their response to the cue. In both experiments, naming latencies were significantly shorter when the two words were semantic associates than when they were nonassociates. These results suggest that processes related to the response-execution stage of the word-recognition process play an important role in semantic-context effects.
\end{abstract}

Facilitation of word recognition by semantic context has been shown to occur in a variety of experimental situations. For example, in a series of studies involving the classification of successive letter strings as either words or nonwords, Meyer, Schvaneveldt, and Ruddy (1975) have demonstrated that less time is needed to classify a letter string (e.g., butter) as a word when it is preceded by a semantically associated word (e.g., bread) than when it is preceded by a nonassociated word (e.g., nurse). Meyer et al. (1975) have also found a similar facilitation when subjects are required to pronounce the second of two successive letter strings. In a variant of this latter procedure, Dallas and Merikle (1976) have shown that the naming latency for one member of a pair of simultaneously presented words is faster when the two words are semantic associates. Other demonstrations of the effect of semantic context have been reported by Warren $(1972,1974)$, who found that greater Stroop interference occurs when the base word in the Stroop task is semantically related to a preceding memory set, and by Jacobson (1973), who found that a word masked by a semantically associated word is more readily reported than the same word masked by a nonassociated word.

Most interpretations of the effects of semantic context begin with the notion that the encoding of a word is sufficient to activate the memory representations of semantically related words. However, several different theoretical interpretations have been advanced to explain how this spreading activation facilitates later recognition of a related word. The effects of semantic context have been assigned to the level of stimulus encoding (e.g., Dallas \& Merikle, 1976; Jacobson, 1973; Meyer et al., 1975), access to lexical memory (e.g., Schvaneveldt \& Meyer, 1973), and retrieval from lexical memory (e.g., Collins \& Loftus,

This research was supported by a National Research Council of Canada scholarship to the first author and by National Research Council of Canada Grant APA-231 to the second author. Address for reprints: Department of Psychology, University of Waterloo, Waterloo, Ontario N2L 3G1, Canada.
1975). While it has been recognized that semantic context may facilitate the recognition process at a variety of levels (e.g., Schvaneveldt \& Meyer, 1973), most theoretical interpretations assume that contextual effects occur quite early in the recognition process.

Perhaps because of the tendency to assign semanticcontext effects to an early stage in the recognition process, most investigations have employed techniques in which responses must be made quickly and immediately upon recognition of an item. In an exception to this common procedure, Dallas (Note 1) measured naming latency for one member of a pair of simultaneously presented words in a situation where the report cue was delayed for $1 \mathrm{sec}$ after the offset of the words. Shorter naming latencies were found when the two words were semantically associated than when they were nonassociated, and the magnitude of the facilitation $(40-50 \mathrm{msec})$ was about the same as found in many other investigations of semantic context.

It is difficult to conceive how this effect of semantic context observed by Dallas (1974) can be interpreted in terms of a facilitation in an early stage of the wordrecognition process. Presumably, the $1 \mathrm{sec}$ delay between display offset and report-cue onset should have provided ample time for the subjects to encode both words and to prepare responses. Nevertheless, the subjects were able to name one of two semantically related words faster than one of two nonassociated words. While these results do not necessarily contradict findings indicating that semantic context influences the early stages of the word-recognition process, they do indicate that, under some circumstances, semantic context affects a very late stage in the processing sequence.

Since the later stages of the recognition process are necessarily involved whenever a response to a target word is required, the semantic context effect found by Dallas (1974) conceivably contributes to the differences obtained in the many studies which presumably dealt with "early" effects of semantic context. The present studies were, therefore, conducted because of the impor- 
tance that a demonstration of semantic-context effects at a very late stage in the recognition process has for an interpretation of many effects of semantic context. The first experiment was a replication of the semanticcontext effect originally observed by Dallas (1974). In the second experiment, this effect was evaluated under conditions where it is even more difficult to conceive of a significant influence of early stages in the wordrecognition process.

\section{EXPERIMENT I}

\section{Method}

Materials and apparatus. Forty highly associated word pairs were chosen from the Battig (Note 2) word-association norms. These norms contain free associates for the 300 most frequent four-letter words as determined by Thorndike and Lorge (1944). All words chosen for the present study were monosyllabic, and they varied in length from three to five letters.

The 40 word pairs taken from the Battig norms formed the set of materials used for the associate condition. The stimulus items from the norms were always the reported or target words for the pairs. For the nonassociate condition, the forty stimulus items were randomly paired with the 40 associated words.

The word pairs for each condition were typed in black uppercase letters (IBM Crator) on white cards. When viewed through the tachistoscope, each word subtended 43 to $52 \mathrm{~min}$ of visual angle and the vertical separation between the two words was approximately $1 \mathrm{deg}$ of visual angle. Each word pair was typed on two separate cards: One card contained the reported word in the top row and the paired word in the bottom row; the other card had the reported word in the bottom row and the paired word in the top row. A total of 160 cards, 80 for each condition, was thus prepared.

The report cue consisted of a long bar, subtending approximately $52 \mathrm{~min}$ of visual angle, presented to each side of the reported word. A much shorter pair of bar markers, subtending approximately $17 \mathrm{~min}$ of visual angle, bracketed the nonreported word. Bar markers bracketed both words to avoid possible problems due to lateral masking selectively acting on the reported word.

The word pairs were presented by means of an Iconix fourfield tachistoscope. Response latencies were recorded to the nearest millisecond by an Iconix time base and counter (Model 6255), which was stopped by a Hunter voice-operated relay (Model 3205).

Design. Three within-subjects variables were studied. There were two blocks of 80 trials each. Within each block of trials, half of the word pairs were associated words and the remaining pairs were nonassociated words. Each of the 40 target words was presented twice in each block of trials, and the particular pairs used were arranged so that each target word appeared once in the top row and once in the bottom row. Within the above constraints, the order of presentation for the 160 cards containing word pairs was randomized independently for each subject.

Procedure. The luminance of all fields of the tachistoscope was set at approximately $70 \mathrm{~cd} / \mathrm{M}^{2}$. On each trial, the subjects first fixated a small black dot located in the center of a blank white field. The fixation dot was located in a position that was centered between the two words in each pair. When given a verbal ready signal, the subjects pressed a hand-held switch which activated the tachistoscope. Each word pair was then presented for $150 \mathrm{msec}$, and immediately following the presentation of a word pair, a blank white field was presented for $1 \mathrm{sec}$.
The report cue, indicating whether the top or bottom word should be reported, was presented for $250 \mathrm{msec}$ at the offset of the blank white field. Following the presentation of the report cue, the tachistoscope returned to the fixation field. There were approximately $10 \mathrm{sec}$ between trials.

After the presentation of each word pair, the experimenter recorded whether the correct word was given and the response latency. Response latencies were recorded from the onset of the report cue.

The subjects were told prior to the beginning of the experiment that the presented material would always be two common English words and they should report the cued word as quickly as possible. To familiarize the subjects with the procedure, 30 practice trials were given prior to the experiment proper. All word pairs for the practice trials consisted of different words than used in the experiment.

Subjects. The subjects were eight volunteers recruited from undergraduate psychology courses of the University of Waterloo. All subjects were paid $\$ 2$ for their services.

\section{Results and Discussion}

Since the present experiment was a replication of a previous study by Dallas (1974), the data from both studies were combined, with Replications considered a factor in the analyses. Mean and median RTs were determined for each subject based upon the number of correct responses for the 20 trials in each experimental condition. Both the means and the medians were analyzed by a 2 by 2 by 2 by 2 analysis of variance to evaluate Replications, Trial Block, Row Reported, and Associative Context. Since the analyses of the means and the medians revealed identical patterns of results, only the data and the analysis based upon the mean RTs are presented.

The analysis revealed neither a significant main effect of Replications $[F(1,14)<1]$, nor any significant interactions involving the Replications factor [all $\mathrm{Fs}(1,14)<2.30$ ]. It appears that similar patterns of results were obtained in the two replications. The mean RTs and error rates presented in Table 1 are therefore collapsed across the two replications.

As indicated by an inspection of Table 1, naming latencies were faster in the second block of trials $[F(1,14)=15.78, p<.01]$, and, in general, words presented in the top row were named faster than words presented in the bottom row $[F(1,14)=6.16$, $\mathrm{p}<.025]$. More importantly, in all conditions the naming latencies were faster for words accompanied by a semantic associate than for words paired with a non-

Table 1

Mean Naming Latencies in Milliseconds for Experiment I

\begin{tabular}{llllll}
\hline & & \multicolumn{3}{c}{ Nonreported Word } \\
\cline { 3 - 6 } & & \multicolumn{2}{c}{ Associate } & \multicolumn{2}{c}{ Nonassociate } \\
\hline \multirow{2}{*}{ Block 1 } & Top Row & 677 & $(3)^{*}$ & 699 & $(8)$ \\
& Bottom Row & 677 & $(9)$ & 779 & $(22)$ \\
\multirow{2}{*}{ Block 2 } & Top Row & 576 & $(2)$ & 628 & $(5)$ \\
& Bottom Row & 605 & $(3)$ & 642 & $(12)$ \\
\hline
\end{tabular}

*Percent errors 
associated word $[F(1,14)=8.66, p<.01]$. In the first block of trials, this facilitation in naming latency produced by semantic context was considerably larger when the bottom row was cued. In the second block of trials, however, semantic facilitation was approximately the same for words presented in the top and bottom rows. This pattern of results led to a significant Trial Block by Row Reported by Associative Context interaction in the analysis $[F(1,14)=9.77, p<.01]$ and suggests that subjects initially tend to process the displays in a top-to-bottom order (cf. Dallas \& Merikle, 1976).

Most previous research dealing with the effects of semantic context upon word recognition has been conducted within experimental paradigms which use an immediate, speeded response as the dependent variable. Within these paradigms, it is reasonable to attribute effects of semantic context to the initial stages of the word-recognition process. The present experiment demonstrates, however, that semantic context also influences response latency even when the response is not initiated until more than $1 \mathrm{sec}$ after the onset of a display. The implication of this result is that semantic context may not necessarily facilitate the initial stages but may have its effect at a very late stage in the wordrecognition process.

However, one aspect of the present data suggests that differential initial processing may, in fact, be determining the RT differences. As indicated in Table 1, errors were more frequent when the two words were not semantic associates. These differential error rates suggest that poorer initial encoding of the words in the nonassociated condition may be the factor responsible for the RT difference observed following the $1 \mathrm{sec}$ cue delay.

The second experiment was designed to provide a more stringent test of the presence of a semantic context effect upon a late stage in the word-recognition process. Onset of the report cue was again delayed for more than $1 \mathrm{sec}$ after the onset of the word pairs, but presentation of the word pairs continued until the subjects initiated their response to the cue. By extending stimulus presentation until response initiation, errors should be considerably reduced. More importantly, any effect of semantic context demonstrated in this situation would be difficult to attribute to a facilitation of the initial stages in the word-recognition process.

\section{EXPERIMENT II}

\section{Method}

General. With one exception, the method was the same as followed in Experiment I. The exposure duration for the displays was increased so that each display remained in view until the subjects responded. In other words, each display was presented for $1,150 \mathrm{msec}$ prior to the presentation of the report cue, and presentation of the displays terminated when the subjects initiated their response to the cue.

Subjects. Two groups of eight subjects were tested. The testing of each group was separated by approximately 1 month.
All subjects were undergraduates at the University of Waterloo and were paid $\$ 2$ for their services.

\section{Results and Discussion}

For each subject, mean and median RTs were determined in the same manner as in Experiment I. These scores were submitted to a 2 by 2 by 2 by 2 analysis of variance to evaluate Replications, Trial Block, Row Reported, and Semantic Context. As in Experiment I, analysis of the means and the medians revealed identical results. Therefore only the mean RTs are presented in Table 2.

The data in Table 2 are collapsed across the two replications, since the analysis revealed neither a significant main effect of Replications $[F(1,14)<1]$ nor any significant interactions involving the Replications factor [all $\operatorname{Fs}(1,14)<1.52$ ]. Naming latencies for all conditions were faster in the second block of trials $[F(1,14)=8.95, p<.01]$ but, as suggested by an inspection of Table 2, this practice effect did not interact with any other variable in the analysis [all $\mathrm{Fs}(1,14)<1]$. There was also no difference in the naming latencies for words presented in the top and bottom rows of the displays $[F(1,14)<1]$.

The most important aspect of the data concerns the effect of semantic context. It can be seen in Table 2 that naming latencies were always shorter when the cued word was paired with a semantic associate than when it was paired with a nonassociated word $[\mathrm{F}(1,14)=13.31$, $\mathrm{p}<.01]$. The average facilitation in RT produced by semantic context was approximately $22 \mathrm{msec}$. There were also no errors made by any of the 16 subjects in the experiment.

While the overall effect of semantic context was relatively small, the fact that semantic context facilitated RT under the present conditions indicates that semantic context influences a late stage in the word-recognition process. Any explanation based upon differences in initial processing in the associated and nonassociated conditions appears unlikely, since the pairs of words were presented for more than $1 \mathrm{sec}$ prior to response initiation. Presumably, the subjects should have had ample time both to encode the two monosyllabic words and to prepare the two responses. Nevertheless, semantic-context effects were obtained.

Following Meyer et al. (1975), the word-recognition process may be conceptualized as involving three distinct stages: (1) stimulus encoding, (2) lexical memory

Table 2

Mean Naming Latencies in Milliseconds for Experiment II

\begin{tabular}{llcc}
\hline & & \multicolumn{2}{c}{ Nonreported Word } \\
\cline { 3 - 4 } & & Associate & Nonassociate \\
\hline \multirow{2}{*}{ Block 1 } & Top Row & 582 & 605 \\
& Bottom Row & 591 & 604 \\
\multirow{2}{*}{ Block 2 } & Top Row & 560 & 588 \\
& Bottom Row & 564 & 589 \\
\hline
\end{tabular}


retrieval, and (3) response execution. Given the relatively long delay between stimulus onset and response initiation, it does not seem reasonable to attribute the present semantic-context effect to either the stimulus encoding or lexical memory retrieval stages of the recognition process. The only alternative is to attribute the observed facilitation to some process involved in response execution.

The implication of the present studies for the interpretation of semantic-context effects is quite clear. Since the response-execution stage is necessarily involved whenever a response to a target word is required, semantic facilitation at this stage may contribute to the observed differences in situations which require an immediate, speeded response. While the present findings do not rule out a contribution of early processing stages, they suggest that caution should be exercised when interpreting the effects of semantic context. In any case, semantic context appears to affect late stages in the word-recognition process, suggesting that any conceptualization of semantic-context effects must consider the contribution of the responseexecution stage.

\section{REFERENCES}

Collins, A. M., \& Loftus, E. F. A spreading-activation theory of semantic processing. Psychological Review, 1975, 82, 407-428.
Dallas, M., \& Merikle, P. M. Semantic processing of non-attended visual information. Canadian Journal of Psychology, 1976, 30, 15-21.

JACOBSON, J. Z. Effects of association on masking and reading latency. Canadian Journal of Psychology, 1973, 27, 58-69.

MeYer, D. E., Schvaneveldt, R. W., \& Ruddy, M. G. Loci of contextual effects on visual word recognition. In $P$. Rabbitt \& S. Dornic (Eds.), Attention and performance $V$. New York: Academic Press, 1975.

Schvaneveldt, R. W., \& Meyer, D. E. Retrieval and comparison processes in semantic memory. In S. Kornblum (Ed.), Attention and performance IV. New York: Academic Press, 1973.

ThorNDIKE, R., \& LORGE, R. A teacher's word book of 30,000 words. New York: Columbia University Press, 1944.

WARREN, R. E. Stimulus encoding and memory. Journal of Experimental Psychology, 1972, 94, 90-100.

WARREN, R. E. Association, directionality, and stimulus encoding. Journal of Experimental Psychology, 1974, 102, 151-158.

\section{REFERENCE NOTES}

1. Dallas, M. R. Association effects and visual selective attention. Unpublished MA Thesis, University of Waterloo, 1974.

2. Battig, W. F. Single-response free word associations for the 300 most frequent four-letter English words. Unpublished manuscript. University of Maryland, 1965.

(Received for publication July $30,1976$. ) 